
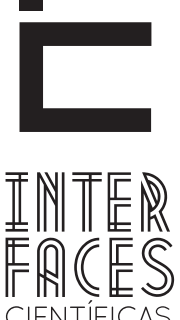

CIENTÍFICAS

HUMANASE SOCIAIS

\title{
A GEOGRAFIA NO CONTEXTO SOCIOPOLÍTICO DA COMUNIDADE DO CONJUNTO PADRE PEDRO: 0 CASO DA E.M.E.F. PROF. LAONTE GAMA DA SILVA
}

Mariana Barbosa Andrade ${ }^{1}$

\section{RESUMO}

0 presente trabalho define o espaço geográfico como um conceito que expressa a relação entre o homem e o meio. Essas características podem ser encontradas na maneira de comer, vestir, no próprio comportamento, na subdivisão do espaço de acordo com as necessidades, valores e crenças. Uma visita técnica e observação em campo na comunidade constataram a ausência do poder público no que diz respeito à infraestrutura do conjunto e principalmente a educação nas escolas da área de estudo. É amplamente relatado pelos moradores do conjunto Padre Pedro, em Aracaju, que a ocorrência de constantes invasões à esco- la e até a agressão física entre os alunos, reflete em grande parte à insuficiência e o fracasso do processo ensino- aprendizagem. Portanto, para solucionar 0 problema em questão é necessário o investimento no ambiente da área e das escolas, o comprometimento da coordenação e dos professores em buscar uma qualidade de ensino.

\section{PALAVRAS-CHAVE}

Espaço Geográfico. Poder Público. Ensino-Aprendizagem. 


\section{ABSTRACT}

This paper defines the geographical space as a concept that expresses the relationship between man and environment. These features can be found in the way of eating, dressing, also, in the behavior and in the division of space, according to the needs, values and beliefs. A survey conducted in the community, using technical visits, field observation, and interviews with residents demonstrate that there is a lack of attention from the government authorities to the community infrastructure, more precisely the education in schools in the educational area. It is widely reported by the residents ofConjunto Padre Pedro in Aracaju, the frequency of invasions in the school and physical aggression among students, largely reflects the insufficiency and the failure of the teaching-learning. Therefore, to solve the problem at hand is the investment in the area and schools environment, involving coordination and teachers to achieve an education with quality.

\section{KEY WORDS}

Geographic Area. Public. Teaching-learning.

\section{INTRODUÇÃO}

A Geografia define o espaço geográfico como um conceito que expressa a relação entre o homem e o meio. Dessa forma, o espaço geográfico pode ser visto por meio de diferentes ângulos, seja de paisagem, território, lugar ou ambiente.

Os lugares ganharam marcas próprias, diferenciando um dos outros ao transformar o espaço natural, registrando a cultura reveladora das tendências de cada povo, características encontradas mesmo em atos, como no comer, no vestir, no próprio comportamento, na subdivisão de seu espaço de acordo com suas necessidades, valores e crenças.

\section{RESUMEN}

Este documento define el espacio geográfico como un concepto que expresiones la relación entre el hombre y el medio ambiente. Tales características pueden encontrarse en la manera de comer, vestirse, el mismo comportamiento en la división del espacio según las necesidades, valores y creencias. La encuesta se llevó a cabo en la comunidad, mediante las visitas técnicas, la observación del campo, y entrevistas con los residentes notó la falta de público con respecto a la infraestructura del conjunto y en particular educación en escuelas en el área de estudio. Es ampliamente divulgado por los residentes del Padre Pedro en Aracaju, la ocurrencia de constantes invasiones por la escuela y agresiones físicas entre alumnos, refleja en gran medida el fracaso de la enseñanza-aprendizaje. Por lo tanto resolver el problema en cuestión es el ambiente de inversión en el área y las escuelas, coordinación deteriorada y profesores para buscar una educación de calidad.

\section{PALABRAS CLAVE}

Área Geográfica. Público. Enseñanza-aprendizaje.

0 fato do ser humano desempenhar algumas atividades em função de sua sobrevivência implica na necessidade de ter abrigo, vestimentas, e de realizar atividades diárias para sobreviver, como em comunidades primitivas, faz com que o homem produza indiretamente a sua própria vida material.

Diante disso, a cidade materializa-se enquanto condição geral de produção, distribuição, circulação e troca de mercadoria. É nesse sentido de produção que irá desenvolver a mais valia e a disputa do uso do solo urbano, disputado pelos vários segmentos da sociedade de forma diferenciada, gerando conflito entre 0 
individuo e o uso. É no centro urbano mais complexo, que se encontram todos os capitais, todos os trabaIhos, técnicas e formas de organização propícia para a prosperidade do homem.

A noção de território diz respeito a um espaço definido e delimitado por e a partir de relações de poder, por isso é essencialmente um instrumento de exercício de poder. Dessa forma, são construídos e desconstruídos podendo ter um caráter permanente, mas, também, podem ter uma existência periódica, cíclica.

Outra forma de abordar a temática da territorialidade é considerar o território como um campo de força, uma teia ou rede de relações sociais, que define ao mesmo tempo um limite, uma alteridade entre a comunidade envolvida e os de fora dela. Essas organizações espaço-temporal podem surgir sem que haja uma delimitação no espaço concreto, conhecidos de territorialidade flexível tais como: território da prostituição, território do tráfico de drogas, dentre outros.

A partir desse contexto, pretende-se investigar 0 seguinte problema de pesquisa: como a escola e a Geografia têm contribuído para o desenvolvimento social da comunidade do conjunto Padre Pedro no município de Aracaju? Com o intuito de definir a escola

\section{A CIDADE E O PROCESSO DE URBANIZAÇÃO}

O processo de urbanização e a cidade, forma concretizada deste processo, marcam tão profundamente a civilização contemporânea, que muitas vezes torna-se difícil pensar que em algum período da História as cidades não existiram, ou tiveram um papel insignificante.

Entretanto, é de fundamental importância entender a história das cidades, pois, todas as transformações oriundas dos processos de destruição e e a Geografia como responsáveis de possibilitar aos cidadãos o domínio de conhecimentos sociais e políticos decorrentes do mundo?

O trabalho teve como objetivo geral Identificar os aspectos sociais e políticos da comunidade do conjunto Padre Pedro, no município de Aracaju; e como objetivos específicos, verificar os programas educacionais para o desenvolvimento social voltado as crianças e jovens; identificar as ações do poder público incentivo a esses programas e avaliar a contribuição da escola para o incentivo social da comunidade do conjunto Padre Pedro.

Para o desenvolvimento da pesquisa adotou-se metodologia baseada no aprimoramento das ideias, a partir da pesquisa exploratória e descritiva, cuja finalidade é analisar o problema de pesquisa por meio de observações e o histórico da área de estudo. A população desta pesquisa é composta pelas pessoas que residem no bairro Santa Maria especificamente no conjunto Padre Pedro.

Seguem, portanto, os elementos teóricos que embasam o estudo, as análises dos resultados e levantamento de campo, seguidos pela conclusão do estudo.

reconstrução a que foram submetidos irão explicar a sua complexidade estrutural e cultura. Em outras palavras:

Entender a cidade de hoje, apreender quais processos dão conformação à complexidade de sua organização e explicar a extensão da urbanização neste século, exige uma volta às suas origens e a tentativa de reconstruir, ainda que de forma sintética, a sua trajetória (SPOSITO, 2004, p. 11). 
Por lugar, pode-se entender como a base da reprodução do espaço apropriável para a vida dos seus moradores como: o bairro, a rua, a praça, e nesse sentido, não seria jamais a metrópole ou mesmo cidade.

Tendo esses dois conceitos, lugar e cidade, as relações que o indivíduo mantém dentro do espaço habitado, são expressas todos os dias por meio dos comportamentos humanos. Portanto, a tríade cidadão, identidade e lugar apontam a necessidade de o homem habitar e apropriar o espaço por meio dos modos de uso. É nesse contexto que:

São os lugares que o homem habita dentro da cidade que dizem respeito a seu cotidiano e a seu modo de vida onde se locomove, trabalha, passeia, flana, isto é, pelas formas através das quais o homem se apropria e que vão ganhando significado dado pelo uso (CARLOS, 1996, p. 21).

A cidade é mais que o aglomerado humano que se formou historicamente num ponto do território, vivendo próximas às outras. Assim, a cidade apresenta-se como um fenômeno concentrado e contraditório, fundamentado numa complexa divisão espacial do trabalho, uma aglomeração que tem em vista o processo de produção norteado pelo trabalho, pela concentração dos meios de produção e pela apropriação privada.

A paisagem urbana refletirá assim a segregação espacial fruto de uma distribuição de renda estabelecida no processo de distribuição. Dessa forma,

No caso do uso produtivo do espaço, este será determinado pelas características do processo de reprodução do capital; é o caso da localização da indústria apoiada pelas atividades financeiras, comerciais, de serviços e da comunicação (CARLOS, 2001, p. 40).

A autora já citada completa ao informar que: "o modo de utilização será determinado pelo valor que, em seu movimento redefine constantemente a dinâmica do acesso ao solo urbano" (2001, p. 41). Isso faz com que os bairros de classe média alta sejam mais valorizados e localizados em áreas centrais, enquanto a população mais pobre procura áreas mais distantes, pois, os terrenos são mais baratos e por sua vez possuem pouca infraestrutura.

De outro ponto de vista, o valor de uso é o sustentáculo conceitual do tratamento geográfico dos problemas de uso de solo. Todavia, a teoria do uso do solo urbano deve ser analisada a partir da teoria do valor, fundamentada na unidade entre valor de uso e de valor de troca. Portanto,

A evolução dos preços, todavia inter-relaciona com as
condições de reprodução do sistema e dos custos gera-
dos pela aglomeração pelo grau de crescimento demo-
gráfico, pela utilização do solo, pelas políticas de zonea-
mento ou de reservas de território e pelas modificações
do poder aquisitivo dos habitantes (CARLOS, 2001, p. 48).

Assim, as classes de maior renda per capita ocupam melhores áreas, com terrenos mais amplos, arborizados, silenciosos e com maiores possibilidades de lazer. Enquanto os de menor poder aquisitivo da sociedade restam as áreas deterioradas e abandonadas.

Neste sentido, "qualquer que seja a organização global dos usos ou do modo de produção do espaço urbano, uma racionalidade, cada vez mais necessária, parece reinar sobre o lugar" (CARLOS, 1996, p. 22). Logo, o lugar é o produto das relações humanas, entre o homem e a natureza, tecidos por relações sociais que modificam o espaço urbano.

Observa-se ainda que "É o no lugar que se manifestam os desequilíbrios, as situações de conflitos e as tendências da sociedade que se volta para o mundial” (CARLOS, 1996, p. 29). Dessa forma, o sujeito pertence ao lugar, como este a ele, pois a produção do lugar liga-se indissociavelmente à produção da vida.

Segundo Souza apudAlmeida (2006, p. 39), ao discutir a temática da territorialidade:

Propõe uma abordagem mais abrangente e crítica, na medida em que sua análise pressupõe não propriamente um deslocamento entre as dimensões política e cultural da sociedade, mas uma flexibilização da visão do que seja território. 
Para se entender o funcionamento da rede urbana, é preciso partir da contratação de nenhuma economia urbana, nem de uma cidade isolada e nem do conjunto delas, pode ser autossuficiente. Isso porque a rede urbana está em permanente processo de transformação, verificado principalmente em frequentes transferências de funções que distorçam a circulação de recursos, fazendo surgir pontos de estrangulamento cuja superação requer novas transformações. Portanto,

0 processo de reprodução estar associado às condições de vida da sociedade em suas multiplicidades de aspectos, e por ela determinado. A reprodução coloca a perspectiva de compreensão de uma totalidade que escapa ao plano do econômico, abrindo-se para o entendimento da sociedade em seu movimento, o que pressupõe a totalidade (CARLOS, 1999, p. 63).

Vale ressaltar, que "numa sociedade fundada sobre a troca, a apropriação do espaço, ele próprio produzido enquanto mercadorias ligam-se, cada vez mais à forma de mercadorias" (CARLOS, 1999. p. 66).

No capitalismo as diferenças de classes sociais são muito grandes, principalmente os relacionados ao da habitação cujo acesso é seletivo, sendo um dos sintomas de exclusão que, no entanto, não ocorre isoladamente.

Fica evidenciado que,

Os grupos sociais excluídos têm como possibilidade de moradia os densamente ocupados cortiços localizadas próximos ao centro da cidade - velhas residências que no passado foram habitadas pela elite e que se acham degradada e subdivididas (CORRÊA, 2002, p. 29).

É nesse contexto, que o Estado atua no espaço urbano modificando as casas autoconstruídas em loteamentos periféricos, conjuntos habitacionais e, também, em favelas distante dos centros. Logo,

É na produção da favela, em terrenos públicos ou privados invadidos, que os grupos sociais excluídos tornaram-se efetivamente, agente modeladores, produzindo seu próprio espaço, na maioria dos casos independentemente e a despeito dos outros agentes (CORRÊA, 2002, p. 30).

A produção destes espaços é uma forma de resistência e de sobrevivência às adversidades impostas aos grupos sociais de renovação que lutam pelo direito à cidade. Portanto,

Resistência e sobrevivência que se traduzem na a apropriação de terrenos usualmente inadequados para os outros agentes da produção do espaço, encosta íngremes e área alagadiças. Trata-se uma apropriação de fato. No plano imediato a favela corresponde a uma solução de um duplo problema, o da habitação e de acesso ao local de trabalho (CORRÊA, 2002, p. 30).

\subsection{A EDUCAÇ̃̃O E A GEOGRAFIA EM QUESTÃO}

Em relação à educação, nessas comunidades a escola desenvolve projetos sociais com o apoio de entidades públicas ou particulares, as quais visitam a escola com o objetivo de verificar a frequência e as notas das crianças que participam do projeto para que com isso possa ter o controle sobre elas com o intuito de retirar essas crianças da marginalidade e dar outras oportunidades por meio da informática, capoeira, karatê, esporte em geral, dança e outras modalidades disponibilizando ônibus para levá-las ao centro onde acontecem as atividades.

De acordo com a coordenadora pedagógica da escola, todo mês cada aluno que participa do projeto solicita uma declaração a escola, informando sua frequência na sala de aula, somente permanece nesse projeto aqueles que possuem $87,5 \%$ de frequência no mês, o equivalente a 4 faltas e não reprovaram. Semelhante frequência, também, é solicitada para receber o dinheiro do Bolsa Família e do Programa de Erradicação ao Trabalho Infantil (PETI).

Aqueles que não participam dos projetos, brincam nas ruas do bairro, sem nenhuma perspectiva de mudança. Em outro contexto, 
Se o espaço é construído pelos homens, ele vai apresentar uma aparência, uma paisagem que será resultada desta construção. Esta aparência, no entanto, é apenas a organização da paisagem como se estrutura em um determinado momento. E isto resulta das relações que os homens mantêm entre si, intermediados pelo trabalho e subordinados ao modo de produção capitalista. 0 espaço que nós estudamos em Geografia tem que ser compreendido, então, como um espaço que vai sendo construído ao longo do tempo, por homens (CALLAI, 1986, p. 17).

Logo, os livros didáticos são extremamente importantes para o aprendizado do aluno, além de serem recursos necessários para o desenvolvimento de práticas pedagógicas. Para a professora de Geografia Spósito apud Oliveira (2002, p. 307),

Há, aqui, um aspecto político, que é o de se oferecer aos alunos, gratuitamente, um dos instrumentos que facilitam o processo de ensinar/aprender; e há outro que é prático, pois a compra em larga escala permite diminuição do preço de aquisição desse material. Tudo parece indicar que há dificuldades para se produzir livros didáticos voltados de forma precípua a atender especificidades de realidades regionais ou locais, o que reforça as possibilidades de se estabelecer uma relação biunívoca entre currículo nacional e livro didático.

Para os geógrafos, as crises de escola são geradas de vários fatores, principalmente pelo modo tradicional de ensino demonstrado pela maioria de professores que ensina em escolas públicas, seja estadual ou municipal. É a Geografia Crítica que fica responsável pela análise de fatos (Histórias reais) que acontecem no espaço geográfico. Para Brabant apud Oliveira (2003, p. 35).

Pode-se dizer que a crise da geografia na escola se resume essencialmente na crise de sua finalidade. Ensinamento com função ideológica, sua eficácia se vê contestada por discursos mais modernos (Economia, Sociologia etc.). Marginalizada no momento de adaptação da escola às necessidades profissionais, a Geografia está minada por sua aparente incapacidade de dar conta das lutas onde o espaço está em jogo.

A preocupação quanto ao domínio espacial refere-se ao seu desenvolvimento no sentido geográfico, pois a concepção do espaço e sua organização são subjacentes à análise geográfica. Almeida (1999, p. 12) destaca ainda que "no ensino de primeiro grau, esses conhecimentos/habilidades devem ser desenvolvidos e aprofundados desde a primeira até a oitava séries, pois são essenciais ao entendimento dos conceitos que possibilitam ao aluno realizar a análise geográfica".

Com todas essas afirmações, é necessário que o educando aprenda a Geografia Física em seu contexto geral e específico para que o mesmo possa compreender os processos em que o planeta Terra vive. E com isso, analisar se sua região (também outras regiões) possui influência da chuva, montanhas, depressões, florestas etc.

Outra abordagem dos ramos da Geografia ensinada no Ensino Fundamental e Médio é a Geografia Humana. É um ramo da Geografia que trata a relação do Homem com os processos sociais, econômicos, culturais e financeiros do espaço em que vive, ou seja, do espaço geográfico. Os problemas humanos persistem maciçamente no cotidiano das pessoas que muitos Geógrafos se preocuparam em estudar bastante a respeito disso.

Para muitos autores, a Geografia escolar sofre bastante. Isso porque a disciplina faz parte do passivo da velha escola, ou seja, a geografia sofre o contragolpe da emancipação das colônias, na hora em que as estruturas nacionais se inserem nas relações de dependência e se diluem nos espaços mais vastos. Para Oliveira (2003, p. 143), "é na escola que uma parte do processo de conscientização e/ou não conscientização se desenvolve. Todas as disciplinas têm papel a desempenhar nesse processo. À geografia cabe papel singular nesta questão".

0 professor de Geografia precisa estar atento nos conteúdos programáticos que irá passar para os alunos. É nele que possuirá a tarefa de mostrar para os educando uma visão total da realidade brasileira e do planeta Terra. 
É necessário que por meio de uma metodologia de ensino demonstrada com segurança e voltada uma postura crítica do educador de Geografia, o aluno formará opiniões sobre os assuntos adquiridos em sala de aula, desenvolvendo sua formação de cidadão esclarecido. Com isso, Oliveira (2003, p. 144) afirma que:

\begin{abstract}
Ou ensinar uma geografia crítica, que forme criticamente a criança, voltada, portanto, para seu desenvolvimento e sua formação como cidadão. Uma geografia preocupada desde cedo com o papel que estas crianças/trabalhadores terão no futuro deste país. Uma geografia que possibilite às crianças, no processo de amadurecimento físico e intelectual, irem formando/ criando um universo crítico que thes permita se posicionar em relação ao futuro, que thes permita finalmente construir o futuro.
\end{abstract}

A realidade brasileira sobre a prática de ensino da Geografia no Brasil é pouco confusa. Para muitos autores, os educadores (de um modo geral) não participam ativamente dos processos educativos em sala de aula. Há somente um processo dialético de dominação, sem que haja um questionamento sobre o conteúdo dos livros didáticos e o produto final deles.

As metodologias de ensino aplicadas na Geografia são importantes para o aprimoramento de muitos conteúdos em sala de aula. De acordo com Spósito apud Oliveira (2002, p. 299).

Do ponto de vista da condução metodológica do processo, delineia-se claramente o interesse da centralização, via: formulação de parâmetros curriculares nacionais (PCN's) para o ensino fundamental e médio, elaboração de diretrizes curriculares nacionais para o ensino superior, realização do exame nacional de ensino médio (ENEM) etc.

0 processo de ensino-aprendizagem da Geografia precisa ser mais interativo entre professores e alunos. 0 importante desse processo é o domínio do conteúdo do professor, a utilização do livro didático, a função das pesquisas e viagens de campo e conteúdos sendo programáticos para os alunos possuírem um nível de aprendizado e um conhecimento maior da disciplina geográfica.

\subsection{A GEOGRAFIA E A ESCOLA}

O bairro Santa Maria possui cinco escolas do ensino fundamental, sendo três da rede pública estadual e duas na rede municipal.

Segundo o professor de geografia da Escola Municipal do Ensino Fundamental Professor Laonte Gama da Silva, Alexandre do Rosário, a escola no seu cotidiano enfrenta diversos problemas, dentre eles o desinteresse dos alunos. Apesar de a comunidade participar das decisões da escola, por meio de um representante da comunidade, a prefeitura fornece materiais que facilitam a aprendizagem dos alunos, como giz de cera, lápis de cor, isopor, cartolina, cola, tinta guache, dentre outros. Além de fornecer transporte aos alunos e professores, principalmente de Geografia, realizam pesquisas de campo, visando à exploração e conhecimento das belezas naturais da região de Aracaju.

De acordo com a coordenadora Sandra Maria da Mota, para suprir as necessidades, a escola conta com recursos provenientes do FNDE para suprir as demais despesas como a compra de computadores, impressoras, televisões, DVDs, bolas, redes, cones, para incentivar o esporte.

Além disso, a escola procura atrair os alunos para as atividades como festa de dia das mães, festival das barracas (celebração do São João), festa de dia das crianças, feira de ciências e cultural, gincana cultural e jogos internos promovidos pela prefeitura, em parceria com as escolas públicas municipais. Todas essas atividades contam com a parceria da prefeitura que fornece todo o material necessário como a contratação de músicos, palhaços, som e iluminação para a encenação de peças teatrais, merenda de acordo com o período festivo.

Um dos maiores desafios do professor de geografia é o de estimular os seus alunos a refletir para um estudo crítico, com o objetivo de construir um diálogo 
interdisciplinar que contribua para a decifração das coisas e objetos que acontecem no mundo, seja de caráter político ou social. Para isso, o educador procura de forma criativa informar, por meio de jornais, revista, maquetes, trabalhos com reciclagem, mapas, matérias de internet que demonstre a cultura de diversos países e relacionar ao cotidiano dos alunos. É importante salientar que as caminhadas e palestras com o intuito de divulgar acontecimentos do mundo são importantes para a construção do cidadão.

Portanto, analisar, compreender, entender e informar os conflitos sociais e políticos decorrentes do mundo são ações que o professor de geografia deverá expor para os seus alunos como forma de devolver o potencial crítico dos alunos.

\section{CONCLUSÃO}

0 estudo sobre a Geografia como instrumento social e político na comunidade do conjunto Padre Pedro no município de Aracaju, foi de fundamental importância para o desenvolvimento deste artigo. Isso, porque foram identificados aspectos sociais, políticos e geográficos, bem como a relação entre geografia e a escola e seus reflexos nos jovens da comunidade.

A importância da atividade Geográfica, artística e demais áreas da educação têm a função de ensinar a comunidade a conhecer, divulgar, e preservar o patrimônio escolar. Além disso, traz algumas referências sobre a prática do social e político com a questão do desenvolvimento local e os conflitos gerados com as comunidades envolvidas diretamente com esse tipo de atividade, principalmente no que tange a preservação de materiais que compõe a estrutura escolar.

Portanto, o desenvolvimento da ciência Geográfica repõe problemas de profundidade extraordinária:

os alicerces da sociedade moderna, a intensidade de ocupação populacional dos espaços geográficos, o predomínio da razão sobre as outras dimensões humanas. Com o intuito de definir a Geografia e a escola como responsáveis de possibilitar aos cidadãos o domínio de conhecimentos sociais e políticos decorrentes do mundo. Além disso, interfere no destino da sociedade, da cultura e do individuo.

No Conjunto Padre Pedro, a relação entre a Geografia, a Escola e a comunidade deverão manter interdependência com as práticas educativas que envolvem o meio político e social do conjunto, buscando o processo de formação do homem cidadão.

Essa orientação deverá ser realizada desde os primeiros anos escolares, tendo a Geografia e as ciências humanas e artísticas como fatores decisivos para a aplicação da conscientização política e social da comunidade. 


\section{REFERÊNCIAS}

ALMEIDA, Miguel Renato. Favela, arte e juventude: pensando a relação entre ações artístico-culturais e identidade no Aglomerado da Serra em Belo Horizonte. 2006. Minas Gerais. Disponível em: <http://www. bdae.org.br/dspace/bitstream/123456789/1552/1/ tese.pdf>. Acesso em: 13 out. 2009.

ALMEIDA, Rosângela Doin de. 0 espaço geográfico: ensino e representação. São Paulo: Contexto, 1999.

CALLAI, Jame Luiz. Área de Estudos Sociais. Ijuí: Unijuí, 1986.

CARLOS, Ana Fani Alessandri. A cidade. São Paulo: Contexto, 2001.

CARLOS, Ana Fani Alessandri. Novas Contradições do Espaço. In: DAMIANI, Amélia L.CARLOS, Ana Fani
Alessandri; SEABRA, Odete Carvalho de L. (Orgs). 0 espaço no fim de século: a nova raridade. São Paulo: Contexto, 1999, pp 62-74

CARLOS, Ana Fani Alessandri.o lugar no/do mundo. São Paulo: Hucitec, 1996.

CASTRO, Iná Elias de, CORRÊA, Roberto Lobato, GOMES, Paulo César da Costa, (Orgs), Geografia: conceitos e temas. Rio de Janeiro: Bertrand, 2003. pp. 77-116

CORRÊA, Roberto L. 0 espaço urbano. 4. ed. São Paulo: Atlas, 2002.

OLIVEIRA, Ariovaldo Umbelino de. Para onde vai o ensino da Geografia? São Paulo: Contexto, 2003.

SPOSITO, Maria E. B. Capitalismo e urbanização. 14. ed. São Paulo: Contexto, 2004. 


\section{APÊNDICES}

\section{QUESTIONÁRIO DE ENTREVISTA}

Quais os turnos de funcionamento e o número de alunos da escola?

Qual A Estrutura Administrativa Da Escola?

Que Dificuldades A Escola Enfrentadas No Seu Cotidiano?

A Comunidade Participa Das Decisões Na Escola? De Que Forma?

Como Se Processam As Interações Professores-Alunos?

O Governo Está Atendendo As Necessidades Da Escola? Os Recursos São Suficientes?

Explique Os Recursos Que A Escola Recebe?

Quais As Atividades De Educação Ambiental Desenvolvidas Pelos Alunos?

Quais São As Principais Atividades Sócio-Culturais Desenvolvidas Na Escola?

Em Qual Série Há Maior N De Reprovações? A Que Você Atribui? Como A Escola Se Apresenta Em Termos De Reprovação E Evasão Escolar?

A Maioria Dos Alunos Participam Das Atividades Escolares ( Pesquisa, Gincanas, Feiras De Ciências)

A Escola Promove O Planejamento Curricular? De Que Forma?

Que Ações A Escola Desenvolve Para Melhorar O Indice De Reprovação Da Escola?

De Que Forma A Escola Incentiva Aos Alunos A Prática Da Educação Ambiental Na Sua Comunidade?

Quais os Reflexos Da Educação Ambiental No Despertar Da Consciência Ecológica? As Práticas Educativas Enfocam O Turismo E O Meio Ambiente Local? 
- 31 .
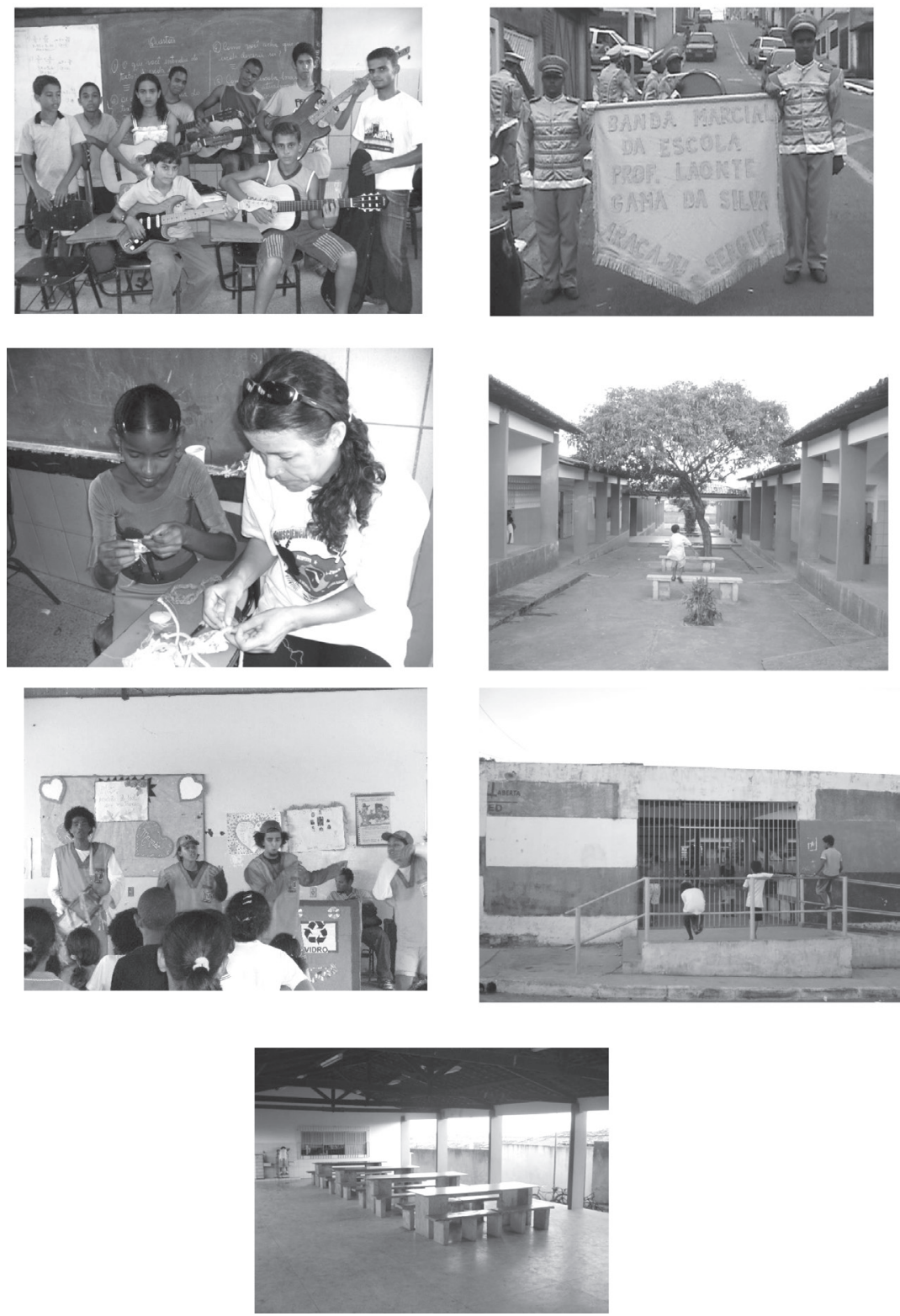

Recebido em: 2 de Maio de 2013

Avaliado em: 16 de Dezembro de 2013

Aprovado em: 18 de Dezembro de 2013

1 Graduada em Geografia pela Universidade Tiradentes e Pós-graduada em Metodologia e Didática do Ensino Superior pela Faculdade São Luis. E-mail: barbosa.andrade@ibest.com.br 